\title{
Electro-optics short course
}

\author{
E. Fjarlie
}

E. J. Fjarlie, "Electro-optics short course," Proc. SPIE 9665, Tenth International Topical Meeting on Education and Training in Optics and Photonics, 96651L (3 June 2007); doi: 10.1117/12.2207333

SDIE Event: Tenth International Topical Meeting on Education and Training in SPIE. Optics and Photonics, 2007, Ottawa, Ontario, Canada 


\title{
Electro-Optics Short Course
}

\author{
EJ Fjarlie \\ The Royal Military College of Canada, Department of Mechanical Engineering, Kingston, ON, K7L 2B4*
}

\begin{abstract}
A two-week short course in optics and photonics was organized and presented at the Royal Military College of Canada, Kingston, ON, from 1988 to 1995. It was designed for personnel in the Canadian Forces who were entering management positions that required some understanding of optics and photonics. The course attracted between 15 to 22 participants every year; individuals came from the ranks of Warrant Officer, through to L/Col, as well as civilian. Variations and improvements were made over the years. A history of events: the course, the personnel, the circumstances, the financing, some of the difficulties and successes, are presented. Much good will, trust, and integrity, were needed by all to bring it to fruition. Suggestions are given.
\end{abstract}

\section{Introduction \& History}

I came to RMC in the Fall of 1976 to do research and to teach in the Mechanical Engineering, ME, Department. Having come from an optics and photonics background ${ }^{(1)}$ and where I had organized many short courses, I was uniquely qualified to propose new programs. However, there were problems and hurdles to overcome lasting a number of years before to bring an optics and photonics course to fruition.

Initial discussions about a short course were broached to the Director Individual Training, DIT, at National Defense Headquarters, NDHQ, in 1980. It did not involve training on specific equipment so the proposal for a course of a few days duration was destined for rejection. The Directorate Avionics, Simulator and Photography, DASP, was approached later. DASP had its focus on optics and photonics, but again the proposal was not accepted. Under Treasury Board and Department of National Defense, DND, rules, it was not allowed to ask outside DND for financial support.

In 1982, I was privileged to visit CFB Greenwood and toured the flight line where the CF140, Aurora, was based. Personnel there were not allowed to open many of the electro-optic sub-systems for observation and to attempt simple repairs! An entire unit that was deemed unserviceable would routinely be sent back to the manufacturer. Nice for the manufacturer to build into his repair and overhaul contract such a condition; costly to the taxpayer; frustrating for the operators, repair, and maintenance personnel, especially when they want to understand. It was a revelation that I, a visitor from RMC, could explain: how components worked in the different sub-systems, the detail within the thermal imager, and warning systems, and explain why certain characteristics were the norm.

This visit rekindled the short course proposal. It was aimed at: personnel with a non-optics background who were in or about to be posted to project management positions that required some optics and photonics; and other personnel who desired to fill this gap in their knowledge were likely to be interested too.

There were hurdles: The main one was that DND was(still is) focused on training, and less on developing an educational program. The DND tendency, when a lack of knowledge is uncovered, is to send the individual(s) on a short course somewhere (anywhere!) that hopefully comes close to fill the lack. A course that anticipates a potential lack is deemed education and is unlikely to get support.

Another problem for any course is the time required that participants need to be away from their desks.

* Current address: EJ Fjarlie, PEng, 100 Medley Court, Unit 52, Kingston, ON, K7K 6X2; tel 613542 9695; e.fjarlie@ sympatico.ca. Current appointments:: Adjunct Professor, RMC,( renewed three times), and Subject Matter Expert, SME, Electro-Optics, NDHQ, MHPMO, Ottawa, ON, for the CF148, Cyclone, the helicopter replacement for the Sea King.

Tenth International Topical Meeting on Education and Training in Optics and Photonics, edited by Marc Nantel, Proc. of SPIE Vol. 9665, 96651L · C 2007 SPIE, OSA, IEEE, ICO doi: $10.1117 / 12.2207333$ 
The proposed Electro-Optics Short Course was for two weeks. Typically, a short training course is one to three days. A longer time has great difficulty to overcome the hiatus from the post. Adding to this are: funds for travel, accommodation, and living costs.

A third hurdle was money and time for lecturers. RMC is geared towards undergraduate teaching with a typical teaching assignment of two undergraduate courses per term. There is little time for faculty to prepare other programs let alone an extra-ordinary program; no funds were available for visitors.

A fourth problem was credibility; while I might be known in the research community, I was not known within DND. My appointment and visibility, such as it was, was in ME, not in "Optics and Photonics". The conservative DND attitude does not associate optics and photonics with ME even though perhaps $50 \%$ of any optics system's cost is for its mechanical design.

The fifth problem was that the window of opportunity for lectures is short. The timing has to fit into the RMC teaching year as well as into DND work schedules. The military community sets aside time for postings to new jobs in the summer months; families are then not tied to their children's school schedule. Late May or early June also offered the best possibility for a hotel to avoid tourist competition for rooms.

A sixth hurdle arose out of the reason for proposing the short course. The personnel in most need had graduated with commerce, or arts degrees, or perhaps were non-commissioned officers with no degree at all. Cross training or "re-posting" is constantly practiced by DND for there are not enough personnel in any one discipline. The course could not depend on mathematics.

A seventh problem was that the participants had been out of the education stream for several years, some for 15 years or more! It was going to be a challenge to re-introduce participants to a new subject, keep their interest, and indicate its utility.

An eighth problem was a personal one: I had worked all my career, roughly 14 years in Quebec, in English; but came to RMC in 1976 to work in (shaky) French and needed considerable time to organize and prepare all my undergraduate lectures. Time was at a great premium to prepare any course.

Encouragement was provided by the department head, the dean, and the principal; encouragement, but no money, nor relief from undergraduate lecturing. This was a volunteer activity.

It was obvious that the short course proposal needed a champion in Ottawa. That champion was the first master's graduate from the optics and photonics PG program ${ }^{(2)}$. Two proposals were submitted. The first, in 1982, was not aggressively pursued and failed, but the second was accepted. The first Electro-Optics Short Course ${ }^{(3)}$ was advertised, travel funds were found, participants were found, and the time was set aside via DASP, NDHQ. Brig/Gen W Niemy, RMC Commandant, welcomed 15 participants in late June, 1988.

A word about the term Electro-Optics: Electro-optics in the argo of optikers is often identified with crystals, polarization, and the myriad of devices that are manipulated by stresses furnished by an electric or magnetic field. Electro-Optics in military lingo is about detection, identification, and recognition of targets in a field of regard for observations. Since "targets" for the program were exclusively military personnel, the term ElectroOptics was maintained even though the program had a much wider range than an optiker might think.

\section{Organization}

The key to the course lies in discussions from Figure1, The Radiometric Problem. Detection, recognition, and identification, are separated into: sources, the atmosphere, optics, filtering and information control, the detector and/or illuminator (for an active system), and the signal processor. This Figure is the touchstone for the ElectroOptics Short Course. As a reminder to the participants to keep "their feet on the ground", there are discussions of Maxwell's equations, but the equation of importance that was repeated regularly and discussed often, was that for signal capture, $\operatorname{Pr} c d, \lambda,[\mathrm{W}]$, and the conversion to an electrical signal: $e_{s i g}=R_{\lambda} \bullet \operatorname{Pr} c d, \lambda,[\mathrm{V}]$. 


$$
\operatorname{Pr} c d, \lambda=\varepsilon_{\lambda} N \lambda \bullet A_{s} \bullet \frac{A_{c}}{R^{2}} \bullet \tau_{a t m o s, \lambda} \bullet \tau_{o, \lambda}
$$

The symbols taken in order are: emissivity, radiance, source area, collector area divided by range, atmospheric transmittance, optics transmittance, and $R_{\lambda}$ is detector responsivity, [V/W]. Any symbol with wavelength dependence shows the subscript, $\lambda,[\mathrm{nm}$ or $\mu \mathrm{m}]$.

The Electro-Optics Short Course had a combination of lectures and demonstrations spread over two weeks and two evening sessions-about 85 hours in all. The signal capture problem was expanded as needed with discussions of: reflection, refraction, polarization, absorption, transmittance, pixels, SNR, and amplification. Electro-magnetic waves and photons were discussed in detail.

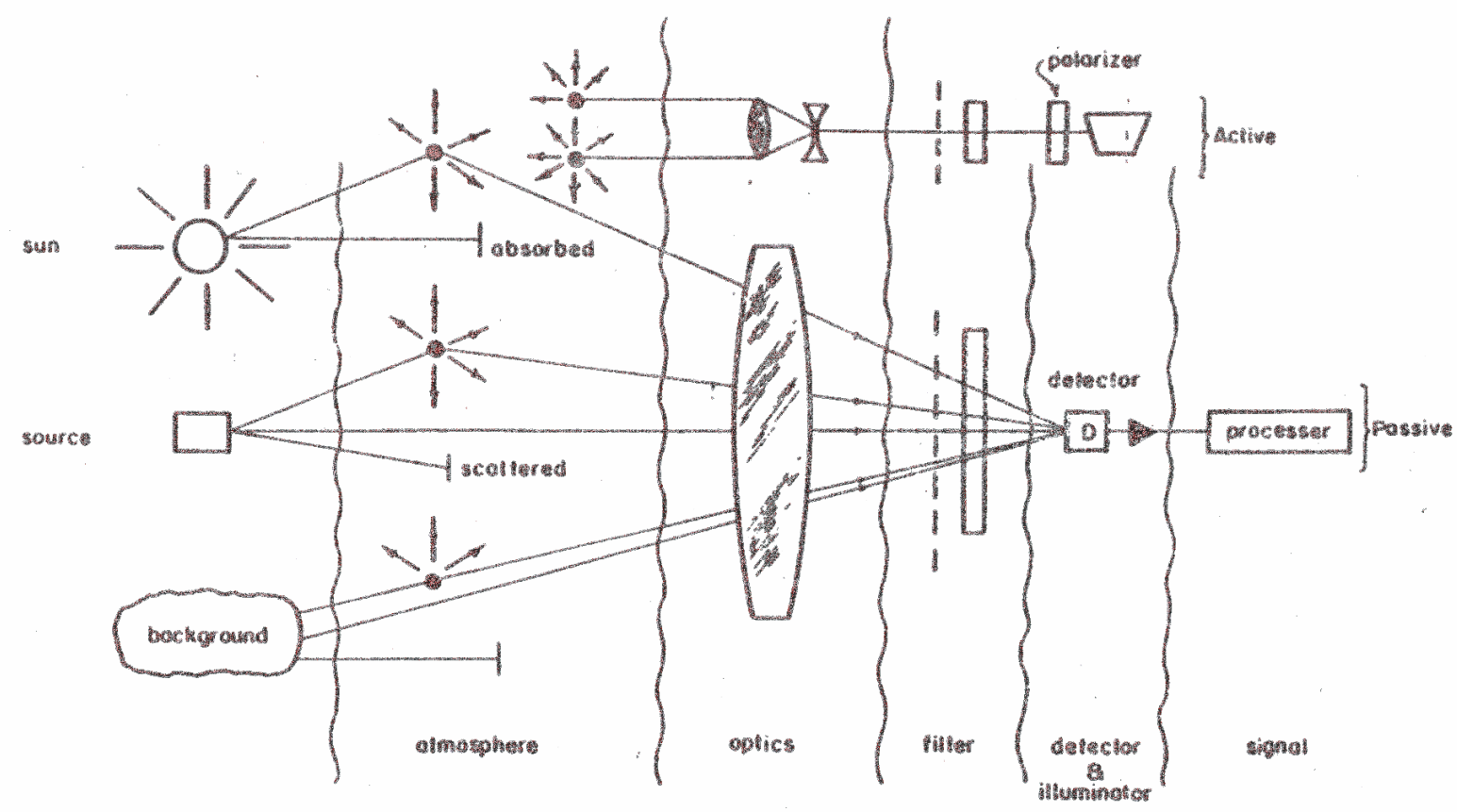

Figure 1. The Radiometric Problem

A discussion of sources-natural, artificial, blackbodies, and lasers-included coherence. There was detail of diffraction, interference, and optical design, with a gentle introduction to Fourier optics and phase. Detector types were explained together with the figures of merit: BLIP and D*. Information control via mechanical scanning, optical and electronic filters, and electronic phase was important. Detector arrays, pixels, and electronic scans were emphasized. Total internal reflection, TIR, prisms, and optical valves, were demonstrated, together with contrast and the modulation transfer function. System figures of merit: the NETD, MRTD, and OTF, and the Johnson criteria completed the course.

The principal lecturer and demonstrator for the activities was me. Colleagues at RMC were approached to present lectures, both as relief for participants who might have to listen to me for too long, as well as for personal relief. Most refused, but Dr T Racey and Dr J Gosselin, Physics Department, agreed. PG students gave a few lectures. Others were drawn by personal invitation from industry and government laboratories ${ }^{(4)}$. Dedication and trust in the purpose to have such a program were the common unifying thought from all. I was proud of all who took the time to deliver lectures. All took the PR opportunity to show their capabilities, to advertise and demonstrate expertise, and to show some products. A few lecturers required travel and living expenses, these were met by ME at RMC; some civilians accepted a small honorarium. Most paid their own way. 
Lectures were from 0800 to 1630 . There were two evening sessions to demonstrate: a 17 [cm] diameter collector astronomical telescope, a 200 line b\&w thermal imager operating with a cooled MCT detector, several different image intensifiers, various binoculars, target designators, and aiming devices. There were a few laboratory demonstrations spaced throughout the two weeks: Ar, CO2, HeNe, and Nd:YAG lasers were operated, optical fibres, and optical fibre sensors that had been built were shown; a 1-m spectrometer and a $1 / 4-\mathrm{m}$ double spectrometer were operated, the use of various polarizers, and filters, completed the demonstrations.

The first course timetabled a late lecture start at 1000 hours the morning following the first evening session (darkness at the end of May comes at 2130 hours!), but the course senior participant, a L/Col, pointed out that "this was somewhat slack". The years following did not attempt such consideration!

Course Notes ${ }^{(3,5)}$ were provided to all participants; lecturers offered hand-outs of materials and brochures, all had static components to show; some presented samples. There was some repetition of material, since the instruction given to the outside lecturers was that their presentation had to be self-contained. The repetition was useful. My 'vetting' of material defined the standard. A revised, re-edited edition of the Course Notes of 227pp was issued in later offerings ${ }^{(5)}$.

There were marked assignments and a final oral examination. Success in the Electro-Optics Short Course was entered into the personnel file of all participants ${ }^{(6)}$.

The first three Courses had participants staying at a hotel in Kingston. Transport from CFB Kingston was used to bring participants to all locations. Using the dormitories at RMC was the way to reduce costs, but RMC cadets in residence from early September to early May, and the requirements for senior cadets removes a further two weeks at each end which placed a stringent constraint on timing. Cost determined that the last five Courses saw the participants in residence in the dormitories.

\section{Results}

The Electro-Optics Short Course was useful ${ }^{(6)}$ and became popular. The average participant number was 17 per year; space in the laboratories limited the maximum to 22. As word spread, inquiries would come in March asking about the Course; there was disappointment when some could not get support from a sponsor ${ }^{(1)}$

At RMC, the Elecro-Optics Short Course was my recommendation for all PG students wanting to start their degree program. It gave an overview for optics and photonics that served as a guide. Because of the timing, not all could take advantage, but most assisted with the lecturing in the following year.

Of the total of 137 participants over the eight years that it was presented: most, about 75 , were from the air element; another 45 were from the land element; 7 were from the maritime element; and there were 10 civilians. There were 8 female and 129 male participants. The preponderant military rank was that of senior Captain.

As the 1996 preparations for the Electro-Optics Short Course were started, word was received from NDHQ that the usual time window was not available, but that an August date was desired. Unfortunately, space in the dormitories at RMC had been taken by the Sea Cadet summer school. Because many in NDHQ were involved as sponsors, it was assumed there that control was with NDHQ, that RMC would be ready to accommodate all. Funds were not available for a hotel alternative so the Course was dropped that year.

When the same period in 1997 arrived, the financial structure had changed at NDHQ, many directorates had been reorganized, and funds were scarce. There was no interest in a two-week course; there was interest in a two-day course, but it was impossible to fit ten days of education into a two day instruction offering; all would be dissatisfied with the "mess".

Inquiries continued to be received from individuals in the CF about the possibility for another ElectroOptics Short Course through 2003. The Course was dead. It was a lack of understanding of what the ElectroOptics Short Course had achieved and been trying to achieve ${ }^{(6)}$ that killed it. 
There is little doubt that such a course is needed. It must be revived. Instead of its RMC location, it could be held in Ottawa, or where travel and living costs are small, or presented on the Internet as a continuing education program. The last suggestion would completely eliminate the need for accommodation, travel, and living expenses, and would allow the course to be stretched over a longer period under control of participants availability.

\section{Acknowledgements}

Maj P Allen ${ }^{(2)}$, DASP, played the key role to pave the way for the Electro-Optics Short Course. Maj E Harrison, NDHQ, (now civilian) kept the momentum going forward. Ms Gerda de Bokx, RMC, administrative assistant (now retired), was vital to keep the details organized.

\section{References}

1. EJ Fjarlie, "Post-Graduate Program in Optics \& Photonics, ETOP '07, Ottawa, ON, (this conference)

2. P Allen, DND, DASP (now at GDC, Nepean, ON), (1981-83, 1987-93)

3. EJ Fjarlie, Electro-Optics Short Course Notes, Royal Military College of Canada, Kingston, ON, (1988)

4. These were: NDHQ (Capt P Allen, Capt J Aubrey, Capt M Sekertra-Bajbus, and others), Ottawa; DREV now CRDC(V) (P Chevrette, Dr. D. Vincent, Dr D Hutt, J, Cruickshank, Dr L Bissonnette, Dr J Boulter, J Delisle, J Dupuis), Valcartier; Dalhousie (Dr B Paton), Halifax; Amoco Laser Group, Illinois; Barringer Research (Dr C Cumming), Toronto; BBM (F Koch) Munich; Interoptics now Lumonics Optics Design, (J Wimperis), Ottawa; Litton Industries (J Wright), Toronto; Optek (Dr A Carswell), Toronto; Optotek (R North), Nepean; Queen's U (Dr G Aitken, Dr J Cartledge), Kingston; SPAR Aerospace (Dr L Gregoris, Dr G Gregoris), Toronto; and Focal Marine, Bedford.

5. EJ Fjarlie, Electro-Optics Short Course Notes, $2^{\text {nd }}$ ed, Royal Military College of Canada, Kingston, ON, (1992)

6. CTS, Occupation Specialty Qualification, "Electro-Optics Fundamentals", OSQ Code 4G, A-P8-004-S4G/PC-000, CFTMPC, (30 Mar, 1993); see also NDHQ/DGRET 